\title{
Daniel Comprère, Puff, bluff et humbug: de Barnum à Jules Verne
}

Isabella Giovinazzo

\section{Q OpenEdition}

1 Journals

\section{Edizione digitale}

URL: https://journals.openedition.org/studifrancesi/38147

DOI: 10.4000/studifrancesi.38147

ISSN: 2421-5856

\section{Editore}

Rosenberg \& Sellier

\section{Edizione cartacea}

Data di pubblicazione: 15 décembre 2004

Paginazione: 641

ISSN: 0039-2944

\section{Notizia bibliografica digitale}

Isabella Giovinazzo, «Daniel Comprère, Puff, bluff et humbug: de Barnum à Jules Verne», Studi Francesi [Online], 144 (XLVIII | III) | 2004, online dal 30 novembre 2015, consultato il 08 mai 2021. URL: http:// journals.openedition.org/studifrancesi/38147 ; DOI: https://doi.org/10.4000/studifrancesi.38147

Questo documento è stato generato automaticamente il 8 mai 2021.

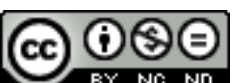

Studi Francesi è distribuita con Licenza Creative Commons Attribuzione - Non commerciale - Non opere derivate 4.0 Internazionale. 


\title{
Daniel Comprère, Puff, bluff et humbug: de Barnum à Jules Verne
}

\author{
Isabella Giovinazzo
}

\section{NOTIZIA}

DANIEL COMPRÈRE, Puff, bluff et humbug: de Barnum à Jules Verne, «Romantisme» n. 116 (II trim 2002) pp. 59-64.

1 L'articolo è dedicato ad una novella di Verne scritta nel 1867, ma poi non pubblicata dall'autore, quale tipico esempio di mistificazione letteraria, costruita sulle curiosità e sugli echi più o meno autentici del discorso scientifico e pseudoscientifico, secondo le modalità di presentazione proposte e divulgate da Philéas Barnum, figura in qualche modo latente anche in altre opere dell'autore. Il testo in oggetto è infatti il racconto di una mistificazione scientifica, simile ad un episodio reale, ovvero il falso ritrovamento di resti fossili di un gigante; il titolo stesso scelto dall'autore, Le humbug, anglicismo tipico dell'epoca proprio per indicare la mistificazione, manifesta chiaramente l'intento del testo, la cui evidenza spiega probabilmente il motivo per cui l'autore abbia scelto di non pubblicarlo. 